\title{
ASPECTOS DA CRÍTICA ONTOLÓGICA COMO FUNDAMENTO PARA O PROCESSO EDUCATIVO
}

\author{
Jorge Sobral da Silva Maia ${ }^{1}$
}

\begin{abstract}
Resumo
Este artigo aborda, em linhas gerais, a discussão do pensamento filosófico ocidental como base para estabelecer a concepção de natureza, sociedade e o papel da ciência e da educação neste contexto. Objetiva discutir o método materialista histórico dialético apresentando elementos presentes neste percurso metodológico. Também analisa aspectos da crítica ontológica como possível embasamento teórico para o processo de formação humana em que o ser social produz suas próprias condições objetivas e subjetivas de existência.
\end{abstract}

Palavras-chave: Crítica ontológica; Educação; Materialismo histórico dialético; Pensamento filosófico

\section{Introdução}

"Hoje é mais fácil imaginar o fim do mundo do que imaginar o fim do capitalismo" 2

A ciência avançou muito na identificação, análise e compreensão de diversos fenômenos sejam eles de caráter físico, químico, biológico ou social. Os pesquisadores se ocuparam ao longo da história em estabelecer a relação de causa e efeito destes diversos fenômenos possibilitando prever suas consequências tanto para o mundo natural, bem como para a sociedade em geral.

Apesar deste avanço a sociedade mundial passa por sucessivas crises cujas bases estão na forma de se produzir a vida nesta sociedade. Vivemos, nestes momentos, um capitalismo pós-democrático com todas as suas consequências para a população mundial, principalmente para os trabalhadores.

O capital financeiro mascara o conflito entre os princípios democráticos e seus interesses nefastos em relação às conquistas sociais, aos direitos humanos, a qualidade ambiental para potencializar a acumulação privada. Contudo, as crises inerentes a este modo de

\footnotetext{
${ }^{1}$ Professor Associado da Universidade Estadual do Norte do Paraná (UENP). É professor do PPG em Ciência Jurídica e do PPG em Educação da UENP Campus Jacarezinho/PR. Professor do PPG em Educação para a Ciência da Universidade Estadual Paulista - UNESP Campus Bauru. Líder do Laboratório de Ensino e Pesquisa em Educação para a Ciência LEPEC. E-mail: sobralmaia@uenp.edu.br - ORCID: 0000-0003-4066-738X

${ }^{2}$ HOLLOWAY, John. Agrietar el Capitalismo: el Hacer contra el trabajo. Buenos Aires: Ediciones Herramienta, 2011.
} 
produzir a vida em sociedade permitem visualizar as estratégias do capital para exercer o domínio mundial sobre a democracia por meio de processos relacionados à tecnologia, às normas fiscais e à dívida pública que massacra os trabalhadores, os autênticos produtores da riqueza.

Ainda, o poder do capital coopta os Estados mundiais, para que estes imponham, por meio dos seus aparelhos repressores e ideológicos, o controle sobre os trabalhadores com o intuito de favorecer o "mercado" e desmontar as formas de enfrentamento destas imposições que vêm sacrificando as importantes conquistas da população.

Desvendar e resistir a essa força hegemônica do capital, passa inequivocamente pela educação das massas populares para reagir a esta tragédia socioeconômica e política. A afirmação não pressupõe uma visão redentora da educação, mas afirmar que não é possível compreender o quadro conjuntural sem ela. Entretanto, é preciso identificar e analisar a diversidade dos processos educativos, mais especificamente o que temos produzido no Brasil para entender que o processo educativo ainda carece de bases para efetivar esta finalidade.

As múltiplas expressões da educação brasileira são problematizadas de diversas formas considerando contextos, fundamentações teóricas, práticas diversas e concepções pedagógicas em realidades díspares e complexas. É relevante considerar que a educação está submetida a aspectos econômicos e políticos que a determinam, pois regulam sua implementação em âmbito municipal, estadual e federal traduzindo, em grande medida, mecanismos de dominação e de subordinação reproduzindo assimetrias de classe, próprias da sociedade do capital.

É neste contexto que propomos discutir, neste texto, o pensamento filosófico ocidental como base para estabelecer a concepção de sociedade e o papel da ciência e da educação. E também apresentar, em linhas gerais o método materialista histórico dialético e alguns de seus elementos para tratar da crítica ontológica como possível embasamento teórico para o processo de formação humana em que o ser social produz suas próprias condições objetivas e subjetivas de existência.

\section{Considerações Sobre o Método}

Neste estudo entendemos que o método necessita partir do conhecimento do objeto com o intuito de capturar a dinâmica estrutural da realidade. Esta afirmação impõe que é a realidade concreta o critério de verdade e as abstrações são reflexos do real que o explica e podem qualificar a práxis humana. Nesse sentido, as categorias de análise expressam os processos sociais, políticos, econômicos em suas determinações históricas. 
Entretanto, é importante afirmar que não é somente a realidade em sua expressão fenomênica a ser considerada, há a necessidade humana em sua subjetividade no mundo, explicitando a relação entre sujeito e objeto em sua complexidade que precisa ser desvelada. Esta intricada relação ao ser esclarecida mostra que a realidade exterior tem seu componente na subjetividade humana, ainda que sua determinação se dê pela realidade concreta. Esta afirmação indica que nessa abordagem metodológica é absolutamente relevante a autoformação do gênero humano, em outras palavras, a dimensão subjetiva compõe com o mundo exterior as determinações da relação sujeito e objeto que origina o conhecimento.

Reafirmamos, nesse sentido, que a atividade vital humana para transformar a realidade necessita de um domínio mínimo da mesma em seu movimento causal e, portanto, de suas leis gerais. Em outras palavras é a ação teleológica oriunda da atividade vital associada à objetividade do conhecimento produzido socialmente e acumulado historicamente, apropriado, em alguma medida, que transforma o real. Esta perspectiva pressupõe uma ontologia dialética e materialista do ser em sua expressão social e, em nossa concepção, essa perspectiva permite a compreensão da gênese e da função social que ocorrem no processo de reprodução social. E, ainda permite apropriar a realidade enquanto o estabelecimento de categorias em totalidade.

A totalidade dialética aqui expressa segundo Maia (2017, p. 192):

[...] Categoria gnosiológica do método materialista histórico dialético, que permite tratar o objeto de investigação em suas relações com os elementos históricos e sociais e não em seu aparente isolamento, explicitando sua gênese, seu desenvolvimento, contradições e relações.

O que se explicita no comentário é uma totalidade articulada entre os diferentes elementos que constituem a sociabilidade humana em sua complexidade materializada na atividade vital ou no trabalho em que os determinantes sociais são fruto dessa atividade no sentido ontológico, como defende Lukács (2013).

Nessa mesma toada a totalidade pressupõe interpretar de forma abrangente e distinta o mundo que nos certa. Essa interpretação segue se ampliando à medida que a reflexão também se amplia, potencializando a análise teórica, e apontando as condições para que a transformação ocorra, ou seja, a construção da crítica subjetiva permite a transformação sobre o sujeito, mas não somente isso, também a transformação das condições reais de existência. Essa modificação, dialeticamente permite o avanço da teoria, constituindo-se a práxis transformadora estruturada no método histórico e dialético. 
O método aqui exposto pode gerar a condição necessária para a transmissão e apropriação das objetivações científicas, artísticas e filosóficas, em seu mais alto nível desenvolvidas pela humanidade ao longo da história, (SAVIANI, 2012).

Essa condição ainda não é uma realidade, mas um vir a ser, como explica Gramsci (1978, p. 47):

A possibilidade não é a realidade, mas é, também ela, uma realidade: que o homem possa ou não fazer determinadas coisas, isso tem importância na valorização daquilo que realmente se faz. Possibilidade quer dizer liberdade [...] mas a existência das condições objetivas - ou possibilidades, ou liberdade - ainda não é suficiente: é necessário "conhecê-las e saber utilizá-las. Querer utilizá-las.

O autor complementa que o ser humano é vontade concreta, uma aplicação efetiva do "querer abstrato ou do impulso vital aos meios concretos que realizam essa vontade." (GRAMSCI, 1978, p. 47). Essa vontade é fruto da atividade social humana que de fato humaniza os seres humanos. Em outros termos a humanidade é produzida histórica e coletivamente pelo conjunto dos seres humanos nos indivíduos singulares (SAVIANI, 2011). A seguir, apresentaremos, ainda que brevemente, um pouco da construção humana, o pensamento filosófico.

\section{O Pensamento Filosófico}

O Pensamento filosófico ocidental trouxe ricas e relevantes concepções de mundo. Platão (1996) em seus ensinamentos traz dois mundos, o das ideias e o mundo sensível. Já para Aristóteles (1996) só há o mundo das coisas e estas não eram regidas pelas ideias. Cada coisa possui potência e ato e assim vai se transformando; Há quatro causas das coisas, a saber, a Material; a Formal; a Eficiente e a final. Nesse sentido, inaugura a teleologia: finalidade última. Deduz-se, pois que as coisas existem porque têm uma finalidade estabelecida pelas ideias que as dirigem.

Platão e Aristóteles ainda que com concepções muito distintas admitiam a razão como elemento de significação da coisas. O modo de entender o mundo é apreender a razão das coisas pelo aprofundamento interior (Platão) ou através da observação e dedução (Aristóteles).

Já na Escolástica, que marca forte domínio religioso, a razão está na mão de Deus e o mundo é sua expressão e para entendê-lo há a necessidade da iluminação. O combate às heresias, ao paganismo e a não aceitação do Divino ocorreria por meio da formulação de teorias racionais e do conhecimento científico. Somente possível pela revelação (nas Confíssões de 
Santo Agostinho) ou Dedução e observação - Deus lógico - (São Tomás de Aquino no Compêndio de Teologia).

O que se verifica nesta perspectiva é a profunda integração entre o humano e a natureza, determinados pela pureza das ideias e pela vontade divina. Desta forma a apropriação do mundo ocorre pela compreensão e percepção dos objetos que o compõe. É a observação e a dedução que determinam a lógica da natureza, esta expressão de um Deus lógico.

A visão grega de mundo não parece superada pela produção filosófica da escolástica. Em essência a resposta para as questões importantes se daria através do conhecimento lógico e racional. Este conhecimento desvelaria os grandes mistérios do mundo. Este processo ocorria paralelo às respostas mundanas relacionadas a essa problemática, dadas pelos seres humanos comuns. A natureza era interpretada pelo pelos mitos, magia e interpretações provenientes da tradição medieval altamente simbólica. Ferry (1994) traz exemplos deste momento histórico apontando a visão orgânica de mundo que mais adiante será confrontada e superada pela visão mecânica de mundo.

Esta visão orgânica é fruto da relação entre as elaborações humanas de caráter subjetivo e objetivo e permitiram certa coerência no desenvolvimento da vida material e abriu portas para outras formas de pensar e atuar no mundo. À medida que as contradições inerentes aos processos humanos vão se estruturando e se cristalizando o ser humano inicia o distanciamento da natureza, começa a ocorrer a ruptura com a concepção escolástica ou orgânica de mundo. Um conflito se apresenta entre grupos humanos em uma mesma sociedade.

O advento da técnica e o avanço social impõem uma nova ordem e a natureza passa a estar a serviço do humano e não mais para atender aos desígnios do divino. É a dessacralização do mundo, evidente, por exemplo, na obra de Bacon (1997) que entende que a natureza precisa ser conquistada e a experimentação é a fonte para o conhecimento real.

Já em Descartes (1999) essa forma de pensar impõe que o universo está formado por duas substâncias, a substância extensa e a substancia pensante. Substância extensa é por ele explicada como aquilo que pode ser medido no universo e, portanto está no âmbito da física. Substância pensante viria de Deus e seria analisada pela metafísica. A partir daí compreendese o mundo como um mecanismo e, além disso, a explicação do mundo deve levar em conta as causas dos fenômenos, estarem de acordo com os princípios da razão e, ainda, descrita em linguagem matemática. 
A visão mecanicista de fundo empírico-analítico possibilita, em grande medida, a separação entre o humano e a natureza, que passa a ser estudada, entendida e dominada para atender às necessidades humanas. De Copérnico a Newton a visão mecanicista experimental confirma a nova ordem do mundo - as leis do movimento, a saber: Princípio da Inércia, A Força e Princípio da Ação e Reação. Também conhecidas como as leis de Newton.

Esta visão mecânica articula-se ao pensamento intelectual apoiado na razão - o iluminismo - que possibilitou inúmeras modificações no âmbito da política, da economia, das artes e da religião. Era a vitória da razão sobre as trevas do irracionalismo e das imposições de ordem religiosa medieval.

Entretanto os adeptos desta idiossincrasia não aplicavam a visão mecânica ao ser humano, este diferia em grande medida, pois detinha propriedades inerentes que somente se concretizariam se fossem dadas as condições necessárias.

Dois gigantes do pensamento contribuíram para avançar na reflexão filosófica. São eles Kant e Hegel. Kant vai explicar que o ordenamento do mundo depende do pensamento que lhe impõe a ordem. Em sua crítica da razão pura (KANT, 1996) o autor esclarece que as leis que regem todas as coisas regem também a nossa forma de pensar.

Em Hegel verifica-se a mesma concepção idealista de que o pensamento determina o real, nítida na tão conhecida e propalada frase no prefácio dos Princípios da filosofia do Direto: "O que é racional é real e o que é real é racional" (HEGEL, 1997, p. 36). Tal afirmação pode ser traduzida pela ideia de que se o real não for construído pela razão ele não será um mundo real. Entretanto, é possível entender que para Hegel a razão se processa por meio da contradição, isto é as leis naturais em confronto determinam a vida e sua plenitude que apresentará uma finalidade em si mesma. É no confronto entre a ideia e o mundo real que se expressa a verdade.

O pensamento filosófico de Hegel ganha expressão materialista na obra de Karl Marx e Friedrich Engels que vêem, como o citado filósofo, a natureza em processo. Entretanto dão notas materialistas à perspectiva dialética, colocando a atividade vital humana - o trabalho com formador de humanidade e a luta de classes como o motor da história.

\section{As Bases para a Crítica Ontológica}

A base ontológica necessária para desvelar o sistema do capital é a mesma que permite sua superação. Esta afirmação está diretamente relacionada ao enfrentamento da problemática contemporânea que se resume nas crises do sistema capitalista que apontam para um colapso 
do modelo engendrado nesta lógica de divisão social do trabalho e acumulação privada da riqueza material e imaterial produzida pela classe trabalhadora.

O sistema do capital é um sistema em crises constantes; são elas econômicas, sociais, políticas, ambientais e são tão profundas que até mesmo os defensores mais entusiasmados desse sistema já as admitem cabalmente.

Estes entusiastas ou intelectuais orgânicos do capital sempre trabalharam para manter este sistema que garante a propriedade privada dos meios de produção e para isso elaboraram e elaboram inúmeras ideologias para sua manutenção. Tais ideologias são expressas por termos diversos como crise da sociedade do trabalho, globalização, pós-modernidade, entre outros que têm o único intuito de perpetuar a exploração do trabalho pelo capital e pelo Estado (MÉSZÁROS, 2002) que em grande medida, tentam justificar e naturalizar o regime que atualmente apresenta-se em uma fase maníaca de acumulação financeira. Este autor ainda aponta que

Vivemos numa época de crise histórica sem precedentes que afeta todas as formas do sistema do capital, e não apenas o capitalismo. Portanto é compreensível que somente uma alternativa socialista radical ao modo de controle metabólico do social tenha condições de oferecer uma solução viável para as contradições que surgem a nossa frente. Uma alternativa hegemônica que, por não depender do objeto que nega, não se deixa restringir pela ordem existente, como sucedeu no passado. Apesar de termos de estar alertas para os imensos perigos que surgem no horizonte, não basta negá-los para enfrentálos com todos os meios ao nosso alcance. (MÉSZÁROS, 2002, p. 21. Destaque do autor).

Um dos perigos apontados pelo autor está na afirmação que no atual momento há uma crise do modelo filosófico e científico instituído na modernidade. E, ainda que essa crise tenha como causa a forma analítica, o pensamento racionalista e determinista, a regularidade das determinações sociais e políticas, a segurança dada pelo estado, em outras palavras, a crise está relacionada à ciência, à objetividade, ao método e à razão, esta última não libertou ser humano. O que se tem então é uma

[...] crítica de caráter epistemológico considerando as limitações da ciência moderna e sua neutralidade axiológica, a fragmentação dos saberes, o não cumprimento da promessa de libertar o ser humano por meio da razão fundamentada na lógica formal. (MAIA, 2015, p. 284).

Assim, na lógica desta crítica epistemológica, o enfrentamento necessário, no nível da superestrutura, está na superação da modernidade por meio de uma "nova" perspectiva cultural 
e intelectual que dê valor aos relativismos, ao cotidiano, à subjetividade. Surgem, por isso, manifestações culturais que apontam para uma suposta superação da modernidade. Seriam essas manifestações denominadas de pós-modernidade.

Como adiantamos anteriormente a pós-modernidade, segundo nossas análises, é mais uma ideologia para perpetuar o sistema do capital. Aponto isso em outro momento:

Uma vez que se considerarmos, em tese, o fracasso da modernidade, pode se pensar a hipótese de uma construção de sentidos com vistas a recompor os elementos políticos, econômicos, culturais, religiosos, entre outros, o que levaria possivelmente ao aparecimento da pós-modernidade. Se de fato é isto, o que se verifica é a ruptura com o estatuto epistemológico da modernidade, ou pelo menos uma tentativa de...

Esta ruptura indica diversas possibilidades, um lócus pós-moderno que despersonaliza o ser humano e na lógica do neoliberalismo globalizado converte-se em mercadoria, sem identificar a possibilidade de mudança, assume certo conformismo que nega a luta de classes. Esse esvaziamento psíquico impõe desvalorização do sentido e ausência de respostas às grandes questões filosóficas. (MAIA, 2015, p. 290).

E ainda explicito nesta mesma análise que

As limitações de caráter reducionistas rompem com a essencialidade do conhecimento e tira do humano sua possibilidade de emancipação e de compromisso político com a transformação social. Também potencializam a subserviência do estado ao capital, pois indica que a participação do estado na organização política, social e econômica da sociedade, é inadequada, já que esta fere as liberdades individuais atribuindo ao mercado à regulação do trabalho e do capital, favorecendo a acumulação privada e a divisão social de classe, fortalecendo o sistema econômico neoliberal (MAIA, 2015, p.191)

Depois dessa breve digressão explicativa retomemos a questão de ser esta ideologia um dos perigos a ser enfrentando para que a perspectiva da crítica ontológica se amplie para explicar e superar o sistema do capital. Contudo, cabe aqui uma explicação antes de avançarmos em relação à categoria ideologia que não consideramos como consciência invertida ou falsa consciência em relação à realidade (MARX; ENGELS 2007), mas como expressões históricas em formação que podem ser, em termos gramscianos, inorgânicas, pois intentam conciliar as contradições do sistema, mascará-las ou naturalizá-las com a intenção de perpetuá-las, conferindo a elas certo caráter absoluto. (GRAMSCI, 1999). Tal concepção é distinta das proposições do Materialismo histórico-dialético que aponta o caráter não absoluto do conhecimento e da realidade, que são determinações sociopolíticas e, por si só, contraditórias e ligadas a uma classe e a suas expressões na história. 
Posto isso, é possível verificar que um ataque aos princípios da modernidade, em tese, serve de fundamento para desqualificar o materialismo histórico-dialético como filosofia e método insuperável de nosso tempo para a explicitação e superação do sistema do capital.

A crítica de fundo pós-moderno ao fundamento Marxiano aponta que essa construção está obsoleta, por tratar questões associadas ao século XIX, que se mostra "mecanicista, determinista, economicista, resultante de uma concepção histórica animada por uma perspectiva teleológica e encoberta por uma aura de cientificidade." (LOMBARDI; SAVIANI, 2008, p. 09).

Os autores ampliam a argumentação que a contraposição em relação ao pensamento moderno e ao materialismo histórico dialético já vinha se cristalizando e que a queda do muro de Berlim ou o fim do socialismo real seria o último respiro da intenção, agora moribunda, da transformação revolucionária da sociedade. Ainda os mesmo autores esclarecem que essa crítica não é nova e apontam que sua motivação é a-histórica e essa contestação já ocorria nos tempos de Marx e Engels.

Todavia, a atualidade do pensamento de Marx e Engels é notória já que é plenamente observável um estágio capitalista que gera uma grande dúvida, a saber: estamos além imperialismo ou em sua fase mais avançada. Seja esta ou aquela resposta, o certo é que a globalização imperialista determinou um marco estrutural ao qual todas as nações necessitavam se incorporar (ACANDA, 2017). O autor também esclarece que

Esta situação encontrou sua expressão no campo das produções de ideias e representações, em todos os níveis [...]. O predomínio da economia capitalista expressa-se em um sentido comum (que permeia também a produção teóricosocial), que legitima os paradigmas básicos do domínio da burguesia mundial. Sem compreender isso, não se pode entender a especificidade do imperialismo atual. Seu domínio não se baseia apenas em seu poderio econômico, político ou militar (que, sem dúvida, existe), mas também em sua habilidade para conformar a produção de ideias, em sua capacidade de uniformizar em escala planetária a produção espiritual, inclusive a de pensamento teórico e a do próprio imaginário da resistência (ACANDA, 2017, p. 130. Destaques do autor)

A exposição do autor nos remete à ideia de hegemonia que pressupõe dois grupos na acepção de Gramsci (1999), a do grupo dirigente e do grupo dominante. É dirigente em relação aos aliados, aqueles que têm os mesmos interesses e se vêm organizados nesses interesses. Já o grupo dominante assume essa posição em relação àqueles que têm interesses diversos. Porém 
o filósofo esclarece que os dirigentes podem sê-lo antes de assumir o poder e quando o assumem se tornam dominantes e continuam a ser dirigentes.

Observa-se então uma rara aproximação entre o conceito de imperialismo e a categoria gramsciana de hegemonia que Acanda (2017) denomina de hegemonia imperialista e a identifica como a atual relação de domínio do capital sobre o trabalho.

Neste caso pode-se perceber que a crítica ontológica pode se ocupar desta problemática da hegemonia imperialista, que articula os aspectos da produção do conhecimento (ciência) e da economia para se manterem na condição de dirigentes e de dominantes. Este embate pode ser travado em diversas instâncias, na política, na economia, nas pautas identitárias, na educação e no ensino, na questão ambiental, todavia é preciso ter claro que é necessário compreender que a

Crítica não só dos mecanismos de reprodução do capital como das forças políticas e culturais predominantes, inclusive das que embasam na perspectiva fragmentária do pós-modernismo. Essa concepção se perde na proposição de lutas exclusivamente setoriais no enfrentamento da barbárie em aproximação, envidando esforços em problemas ambientais, étnicos ou de gênero, sem perceber que é precisamente a generalização da questão operária e do trabalho humano como trabalho abstrato a colocar essas contradições em evidencia e a projetá-las como problema genérico do homem. (DEL ROIO, 2005, p. 19).

O trabalho que compete aqueles que buscam a efetivação da intenção progressista revolucionaria precisa buscar a integração de forças e de outra hegemonia com fundamento na filosofia da práxis. Para isso é preciso a assimilação e apropriação, por meio da crítica ontológica, dos fundamentos que permitem compreender e desvendar os determinantes da sociedade do capital com vista a sua superação.

Parece-nos que o processo educativo e suas especificidades permitem, uma vez que seus campos estão impregnados de ceticismo pós-moderno, do neopragmatismo político e do neoliberalismo econômico, uma análise por meio da crítica ontológica. Trataremos desta questão a seguir.

\section{A Questão do Processo Educativo}

A questão central para discutir o processo educativo na sociedade contemporânea está em considerar que a lógica do capital é incompatível com a ideia de humanização, isto é, formar o ser humano emancipado. 
Partindo dessa premissa consideramos que a educação tem por finalidade formar humanidade no ser humano, permitir o desenvolvimento da autonomia ética e intelectual, de forma a conduzir o individuo singular rumo a sua emancipação política e humana.

Ora se refletirmos que o papel da educação é formar a humanidade nos seres humanos, verifica-se o corolário que o capital e sua essência incompatibilizam com a educação e seus processos. Isto porque a essência do capital e de seu sistema é a desumanização. Entretanto como é um sistema em constante contradição, ele precisa de pessoas com um nível de educação para atender a suas demandas. Mesmo antagonizando a Educação e seus processos, o sistema dela necessita.

Daí precisar de uma escola que forme sujeitos práticos e utilitários. Nesta perspectiva, seus intelectuais, fundamentados em abordagens educativas não críticas produzem ideologias com vista a estruturar hegemonias, elaborar políticas públicas e normatizar processos para colocar a educação, a ciência e toda a produção imaterial a serviço do capital.

Identificar essas estratégias é urgente e os elementos da crítica ontológica, para tal, passam pela compreensão de que o meio social em que se desenvolvem são incorporados pelas professoras e professores. Perceber que permitem formar agentes para atender ao capital e levam ao empobrecimento do processo formativo. Ainda, que o Estado que produz essas estratégias é também um estado do capital e que por vezes o regime dito democrático representativo ou liberal é mais uma ideologia que fortalece o sistema. Em síntese é preciso romper com as teorias e ideias liberais e neoliberais na educação.

Essa ruptura vem se mostrando possível, mas difícil de ocorrer espontaneamente. A possibilidade está presente ao considerarmos as reformas sociais implementadas para atender às necessidades das classes dominantes e retirar direitos dos trabalhadores, cada vez mais sem trabalho, sem saúde, sem educação, famélicos e desprovidos de qualquer amparo significativo por parte do Estado liberal.

Entretanto, é importante frisar que apesar dessas reformas prejudicarem e tirarem direitos da classe trabalhadora, gerando crises comuns a este sistema e promovendo insurreições populares, estas não são suficientes para a constituição de um movimento socialista revolucionário que conduzam à mudança do sistema.

Esse movimento espontaneamente não ocorrerá. É preciso que se organizem ações coletivas que promovam a consciência filosófica das massas, consciência essa que é radical, rigorosa e de conjunto como defende Saviani (2007, p. 20-21): 
Radical: Quer dizer, é preciso que se vá até às raízes da questão, até seus fundamentos. Em outras palavras, exige-se que se opere uma reflexão em profundidade

Rigorosa: proceder com rigor, ou seja, sistematicamente, segundo métodos determinados, colocando-se em questão as conclusões da sabedoria popular e as generalizações apressadas que a ciência pode ensejar.

De conjunto: o problema não pode ser examinado de modo parcial, mas numa perspectiva de conjunto, relacionando-se o aspecto em questão com os demais aspectos do contexto em que está inserido

A constituição da consciência filosófica abre a possibilidade para a elaboração de estratégias objetivamente fundamentadas em direção à reestruturação radical que promova a socialização da riqueza material e imaterial, bem como dos meios de produção.

Produzir a consciência filosófica passa inequivocamente pelo processo educativo, processo esse que se mostra estratégico na luta pelo socialismo. À medida que se avança neste processo potencializa-se a prática social diretamente relacionada às produções materiais e imateriais da vida em sociedade, pois permite identificar e pensar a contradição entre o que se processa diuturnamente no mundo do capital e as produções científicas e filosóficas ajustadas à crítica ontológica que desvela e pode conduzir ao movimento revolucionário.

Qualificar a prática social implica a compreensão de que esta prática humana é teleológica com aponta Lukacs (2012), isto é, uma prática com um fim em si mesma que busca apreender os elementos no entorno do próprio ser humano. Esta apreensão impõe minimamente o conhecimento da intricada rede de relações da sociedade para que se atinja o fim último da prática social. Por isso verifica-se que a realidade é o critério de verdade em se tratando da prática social transformadora. Nesse sentido a pós-modernidade, o pragmatismo político e neopragmatismo, o neoliberalismo em suas artimanhas que, nublam a verdade concreta, dificultam a captura do fato pelo intelecto, por isso devem ser enfrentados como ideologias do capital. Este enfrentamento se dá no plano teórico e prático.

Diante do exposto, evidencia-se a necessidade da crítica em sua dimensão teórica para ampliar a compreensão da dinâmica socioeconômica que nos rege e estabelecer as bases práticas para que se realize, não somente a crítica do capital pelo trabalho, mas crítica do trabalho no capital. (POSTOME, 2014). Mais especificamente o trabalho educativo que se configura em essência como a principal forma de produzir a humanidade nos seres humanos (SAVIANI, 2011). 


\section{Conclusões}

O estudo aqui proposto não apresenta um sistema original de pensamento elaborado, mas uma retomada de uma concepção teórica baseada na décima primeira tese de Marx sobre Feuerbach em que se explicita a ideia de que os filósofos se ocuparam de explicar o mundo de muitas maneiras e cabe a nós promovermos sua transformação.

Com essa orientação fizemos um breve resgate da produção filosófica acidental para indicar as bases que possibilitaram a elaboração histórica para a crítica ontológica. A partir da daí, trouxemos alguns elementos que, entendemos, nos permitem visualizar as bases para a crítica necessária à sociedade capitalista e seu sistema.

Na sequência abordamos fatores ligados à educação e os enfrentamentos necessários a esse campo, bem como seu papel, em linhas gerais, para o enfrentamento das ideologias produzidas pelo sistema do capital. Apontamos sucintamente a necessidade de articular a conceito de hegemonia proposto por Gramsci ao conceito do imperialismo como forma de desvendar, pela análise ontológica, os meandros que mantém o processo opressor sobre a classe trabalhadora.

Essa reflexão nos leva indubitavelmente a entender que é relevante neste debate ter em conta as condições materiais, imateriais, objetivas e históricas da classe trabalhadora e traçar a partir daí as táticas e estratégias para a organização desta classe para si. Isto por que o capitalismo avançou para o imperialismo, uma etapa superior, e se apresenta como capital financeiro imperialista contemporâneo.

A crítica revolucionária precisa ser retomada enquanto práxis voltadas para um processo democrático sobre a égide da classe trabalhadora para implementar um programa de resgate dos valores humanos, dando vida à economia política não mais a serviço da classe social dominante.

Neste particular, o processo educativo necessita assumir o compromisso de formar intelectuais em condições de decifrar as proposições ideológicas dos opressores e propor ações que permitam a emancipação política e humana por meio da educação, da prática social e da reformulação da estrutura do Estado.

De fato conclui-se que o processo educativo é importante agente, não o único, desse processo de transformação da sociedade e precisa se valer do conhecimento científico, artístico e filosófico em seu mais alto nível e da militância organizada pelos intelectuais orgânicos da classe trabalhadora. 


\section{Referências}

ACANDA, Jorge Luis. As raízes estruturais da hegemonia. In Del Roio, Marcos (org.)

Gramsci: Periferia e subalternidade. São Paulo: Editora da Universidade de São Paulo, 2017.

ARISTÓTELES. Poética. São Paulo: Nova Cultural, 1996. Coleção os Pensadores.

BACON, Francis. Novun organum ou verdadeiras indicações acerca da interpretação da natureza. São Paulo: Nova Cultural, 1997. Coleção os Pensadores.

DEL ROIO, M. Os prismas de Gramsci: a fórmula da política de frente única (1919-1926).

São Paulo: Xamã, 2005.

DESCARTES, René. Discurso do método. São Paulo: Nova Cultural, 1999. Coleção os Pensadores.

FERRY, Luc. A nova ordem ecológica: a árvore, o animal, o homem. São Paulo: Ensaio, 1994.

GRAMSCI, Antônio. Cadernos do cárcere, volume 1. Rio de Janeiro: Civilização Brasileira, 1999.

GRAMSCI, Antônio. Concepção dialética da história. 2ed. Rio de Janeiro: Civilização Brasileira, 1978.

HEGEL, Georg W. F. Princípios da filosofia do direito. São Paulo: Martins Fontes, 1997.

HOLLOWAY, John. Agrietar el Capitalismo: el Hacer contra el trabajo. Buenos Aires: Ediciones Herramienta, 2011.

KANT, Immanuel. Criticada razão pura. São Paulo: Nova Cultural, 1996. Coleção os Pensadores.

LOMBARDI, José Claudinei; SAVIANI, Dermeval. Marxismo e educação: debates contemporâneos. Campinas/SP: Autores Associados, 2008.

LUKÁCS, György. Para uma ontologia do ser social, 2. 1ed. São Paulo: Boitempo: 2013

LUKÁCS, György. Para uma ontologia do ser social, 1. 1ed. São Paulo: Boitempo: 2012

MAIA, Jorge Sobral da Silva. Trabalho pedagógico e formação continuada de professores em educação ambiental crítica na escola pública. Ambiência. v. 13 Edição Especial p. 176-194

Dez. 2017. Acesso em 09/08/2020. Disponível em

https://revistas.unicentro.br/index.php/ambiencia/article/view/4795/pdf

MAIA, Jorge Sobral da Silva. Problemáticas da educação ambiental no Brasil: elementos para a reflexão. Rev. Eletrônica Mestr. Educ. Ambient. v. 32, n.2, p. 283-298, jul./dez. 2015.

Disponível em https://periodicos.furg.br/remea/article/view/5544/3452 Acesso 10/05/2020.

MARX, Karl; ENGELS, Friedrich. A ideologia alemã. São Paulo: Boitempo, 2007.

MÉSZÁROS, István. Para além do capital. São Paulo: Boitempo, 2002.

PLATÃO. Diálogos. São Paulo: Nova Cultural, 1996. Coleção os Pensadores.

POSTOME, Moishe. Tempo, trabalho e dominação social. São Paulo: Boitempo, 2014.

SAVIANI, Dermeval. Escola e democracia. 42 ed. Campinas/SP, Autores Associados, 2012. 
SAVIANI, Dermeval. Pedagogia histórico-crítica: primeiras aproximações. 11.ed.rev.Campinas, SP: Autores Associados, 2011.

SAVIANI, Dermeval. Educação: do senso comum a consciência filosófica. 17 ed.rev.Campinas, SP: Autores Associados, 2007.

\title{
ASPECTS OF ONTOLOGICAL CRITICISM AS A FOUNDATION FOR THE EDUCATIONAL PROCESS
}

\begin{abstract}
This article addresses, in general lines, the discussion of western philosophical thought as a basic for establishing the conception of nature, society and the role of science and education in this context. Aims to discuss the dialectical historical materialist method, pointing out essential elements present in the methodological course. It also analyzes aspects of ontological criticism as a possible theoretical foundation for human education process in which the social being produces its own objective and subjective conditions of existence.
\end{abstract}

Key-words: Ontological criticism; Education; Dialectical historical materialism; Philosophical thought

\section{ASPECTOS DE LA CRÍTICA ONTOLÓGICA COMO BASE DEL PROCESO EDUCATIVO}

\section{Resumen}

Este artículo aborda, en líneas generales, la discusión del pensamiento filosófico occidental como base para establecer la concepción de la naturaleza, la sociedad y el papel de la ciencia y la educación en este contexto. Tiene como objetivo discutir el método materialista histórico dialéctico, señalando elementos esenciales presentes en el curso metodológico. También analiza aspectos de la crítica ontológica como posible fundamento teórico del proceso de educación humana en el que el ser social produce sus propias condiciones objetivas y subjetivas de existencia.

Palabras clave: Crítica ontológica; Educación; Materialismo histórico dialéctico; Pensamiento filosófico 